\title{
AQUISIÇÃO \\ DE SENTENÇAS \\ PASSIVAS: \\ UMA RETROSPECTIVA \\ TEÓRICO-EXPERIMENTAL
}

\section{ADQUISICIÓN DE ORACIONES PASIVAS: UNA RETROSPECTIVA TEÓRICO- EXPERIMENTAL}

\author{
ACQUISITION OF PASSIVE SENTENCES: A THEORETICAL-EXPERIMENTAL \\ RETROSPECTIVE
}

Mariana Terra Teixeira

Pontifícia Universidade Católica do Rio Grande do Sul

Gabriel de Ávila Othero **

Universidade Federal do Rio Grande do Sul

\begin{abstract}
RESUMO: Neste artigo, discutimos a aquisição tardia de sentenças passivas, focando nos estudos sobre passivas do português brasileiro (PB). A aquisição tardia das construções passivas já é bem conhecida na literatura, é o chamado "efeito Maratsos": o atraso na aquisição de passivas verbais com verbos de não ação ("ouvir", "ver", "gostar”, etc.). Duas hipóteses são defendidas na literatura para explicar esse fenômeno: a hipótese da maturação de habilidades linguísticas (BORER; WEXLER, 1987) e a hipótese da influência do input linguístico (DEMUTH, 1989; DEMUTH et al., 2010). Neste artigo, procuramos traçar um panorama de ambas as explicações teóricas sobre o atraso na aquisição das passivas e discuti-las com base nos estudos de aquisição de sentenças passivas em PB. Sob viés linguístico teórico-experimental, analisamos alguns estudos-chave e concluímos que eles parecem trazer evidências para se acreditar que a hipótese maturacional fornece uma explicação mais sensata para os dados do PB.

PALAVRAS-CHAVE: Aquisição tardia. Passivas do português brasileiro. Conhecimento sintático.
\end{abstract}

RESUMEN: En este artículo, se discuten la adquisición tardía de oraciones pasivas, centrándose en estudios de portugués brasileño (PB). La adquisición tardía de las construcciones pasivas ya es bien conocida en la literatura, que se denomina "efecto Maratsos": el retraso en la adquisición de los verbos pasivos verbales sin acción (“escuchar”, “ver”, etc.). Dos hipótesis explican este fenómeno en

Doutoranda em Linguística Aplicada pela Pontifícia Universidade Católica do Rio Grande do Sul - PUCRS. E-mail: mterrateixeira@gmail.com

Professor Associado no Instituto de Letras da Universidade Federal do Rio Grande do Sul - UFRGS. E-mail: gabriel.othero@ufrgs.br. 
la literatura: la hipótesis de la maduración de las habilidades lingüísticas (BARRENADOR; WEXLER, 1987) y la hipótesis de la influencia del idioma de entrada (DEMUTH, 1989; DEMUTH et al. 2010). En este trabajo, se ofrece una visión general de las dos explicaciones teóricas sobre el retraso en la adquisición del pasivo y las discutimos sobre la base de los estudios de adquisición de las oraciones pasivas en PB. Nos fijamos en algunos estudios clave de la lingüística teórica y experimental y concluimos que hay pruebas para creer que la hipótesis de maduración proporciona una explicación más razonable para los datos en PB.

PALABRAS-CLAVE: Adquisición tardía. Pasiva en portugués brasileño. Conocimiento sintáctico.

ABSTRACT: In this article, we discuss the late acquisition of passive sentences, focusing on studies in Brazilian Portuguese. Late acquisition of passive constructions is widely discussed in the literature, specially under the 'Maratsos effect': late acquisition of verbal passives with non-action verbs (e.g. hear, see, like, etc.). Two hypotheses are defended in the literature to explain this phenomenon: the hypothesis of maturation of language skills (BORER; WEXLER, 1987) and the hypothesis of the influence of language input (DEMUTH, 1989; DEMUTH et al., 2010). In this paper, we give an overview of both theoretical explanations about the delay in the acquisition of passives and discuss them on the basis of studies of acquisition in Brazilian Portuguese. We analyze the studies of Brazilian Portuguese concerning theoretical and experimental linguistic data, and conclude that they seem to bring evidence to believe that the maturational hypothesis provides a more sensible explanation for the acquisition of Brazilian Portuguese passives.

KEYWORDS: Late acquisition. Passives in Brazilian Portuguese. Syntactic knowledge.

\section{INTRODUÇÃO}

Neste artigo, analisamos estudos teóricos e experimentais com sentenças passivas, focando, ao final, em trabalhos sobre aquisição de passivas do português brasileiro $(\mathrm{PB})$. As passivas são estruturas complexas, com características sintáticas, semânticas e pragmáticas específicas. Trazemos aqui alguns estudos sobre passivas com o intuito de apresentar duas hipóteses sobre aquisição de passivas e argumentar que os dados da aquisição em PB favorecem uma delas, como veremos.

A aquisição de sentenças passivas nas línguas é bastante discutida na literatura (BORER; WEXLER, 1987; DEMUTH, 1989; FOX; GRODZINSKY, 1998, entre outros). Em geral, há um consenso de que há uma aquisição tardia dessa estrutura pelas crianças, o conhecido efeito Maratsos, que é o atraso na aquisição das passivas de verbos de não ação, como ver, ouvir, gostar (MARATSOS et al., 1979, 1985; PINKER, 2009). Como atraso, Maratsos et al. (1979) referem-se à aquisição de sentenças passivas pelas crianças a partir dos seis anos, idade em que, normalmente, as crianças já adquiriram completamente a língua natural de seu ambiente. Para explicar esse fenômeno, duas hipóteses são defendidas na literatura: a hipótese da maturação de habilidades linguísticas (BORER; WEXLER, 1987) e a hipótese da influência do input linguístico (DEMUTH, 1989; DEMUTH et al., 2010). A primeira hipótese tem escopo racionalista e diverge de outras explicações gramaticais, como a proposta do déficit na transferência de papel temático (FOX; GRODZINSKY, 1998). Já a segunda hipótese tem caráter empirista e defende que o input tem um papel informativo crucial, dando relevância à presença de enunciados com estrutura passiva no entorno linguístico da criança.

Para discutirmos o atraso na aquisição de estruturas passivas, organizamos o texto da seguinte maneira: na primeira seção, apresentamos os trabalhos de Borer e Wexler (1987) e de Fox e Grodzinsky (1998), centrados na hipótese da maturação linguística. Na segunda seção, discutimos a explicação de cunho mais empirista do fenômeno, de Demuth (1989) e Demuth et al. (2010), centrada na influência do input linguístico na aquisição da linguagem. Na terceira seção, analisamos os estudos sobre a aquisição de sentenças passivas em PB e fazemos uma correlação desses dados com as teorias resenhadas anteriormente. Finalmente, na última seção, tecemos nossas considerações finais sobre a aquisição de sentenças passivas, com base nos resultados dos trabalhos resenhados - especialmente nos trabalhos que envolveram dados de aquisição do PB. 


\section{BORER E WEXLER (1987) E FOX E GRODZINSKY (1998)}

\subsection{HIPÓTESE DA MATURAÇÃO LINGUÍSTICA: A FORMAÇÃO DE CADEIAS-A}

Borer e Wexler (1987) acreditam que as construções passivas são adquiridas tardiamente devido a propriedades inatas da estrutura da linguagem. Para eles, não há constância dos princípios linguísticos desde o início da aquisição, porque certos princípios da Gramática Universal (GU) maturam em diferentes etapas. A experiência linguística (língua-E) nutre o processo de maturação de alguma forma, mas, além disso, o programa linguístico (a faculdade da linguagem) não é o mesmo em todos os estágios do curso de aquisição. A partir dos princípios existentes na GU, a maturação desse programa da linguagem guia o desenvolvimento linguístico do indivíduo. Certos princípios da gramática, no sentido de uma gramática baseada em princípios e parâmetros, não estariam disponíveis em certas idades do desenvolvimento, pois ainda não estariam “amadurecidos” totalmente. É a Hipótese da Maturação Linguística. Borer e Wexler (1987) questionam a necessidade de assumirmos um sistema linguístico que atue de maneira fixa desde os primeiros meses da criança, uma vez que todos os demais sistemas humanos, partes da cognição humana, estariam submetidos à maturação. Explicar quais princípios do sistema linguístico amadurecem é uma das grandes questões da hipótese maturacional.

No que diz respeito à aquisição de passivas, a formação de cadeias-A é o princípio da gramática que deve ser amadurecido para que a criança consiga compreender e produzir passivas em sua língua materna. Sem que esse princípio esteja amadurecido na sua gramática, a criança não compreende e nem produz adequadamente sentenças passivas verbais (BORER; WEXLER, 1987).

As cadeias-A são cadeias argumentais, formadas pelo movimento de um sintagma nominal (SN) de uma posição argumental para outra posição argumental. Uma posição argumental (posição-A) é uma posição na sentença identificada com uma função gramatical argumental (como sujeito, complemento verbal, complemento de preposição, etc.). As sentenças passivas verbais são um exemplo de estrutura que contém uma cadeia-A:

(1) a) ${ }^{\star}$ Foi chutada a bola pelos meninos.

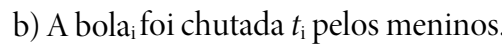

A construção (1a) exemplifica a estrutura de uma construção passiva verbal. Em (1b), podemos ver a frase passiva bem formada, após o movimento-A do SN [a bola]. Esse SN é movido de uma posição-A, a posição de argumento interno do verbo, para outra posição-A, [Spec, IP] (posição de sujeito). O movimento-A se justifica porque o SN deve receber Caso (cf. Filtro do Caso. CHOMSKY, 1980, 1981) em uma posição argumental disponível, uma vez que o verbo está em uma forma nominal, no particípio, e, por isso, perde a capacidade de atribuir/checar Caso. Dessa forma, o SN se move para uma posição em que pode receber/checar Caso, [Spec, IP]. Assim, (1b) exemplifica o movimento A e a decorrente formação da cadeia-A, necessários para a gramaticalidade da sentença passiva verbal; sem a realização desse movimento, a sentença é agramatical - cf. (1a).

As sentenças passivas são um exemplo da "maturação" de princípios linguísticos. Borer e Wexler (1987) sugerem que as crianças não compreendem bem as estruturas passivas até certa idade porque são incapazes de formar cadeias-A. Por isso, as crianças não conseguem compreender nem produzir passivas sintáticas verbais e são bem sucedidas com estruturas que não têm movimento que gere cadeia-A, como as passivas adjetivas. Para Borer e Wexler (1987), a habilidade de formar cadeias-A é inata, mas amadurece biologicamente. Segundo essa hipótese, as crianças adquirem mais cedo as passivas adjetivas - justamente porque essas não formam cadeias-A na sua estrutura - do que as passivas verbais. Em português, a distinção entre passivas verbais e adjetivas é clara, pois as verbais são formadas com o verbo auxiliar ser ("A porta foi trancada"), e as adjetivas com os auxiliares ficar e estar ("A porta estava trancada").

No entanto, em outras línguas, como em inglês, essa distinção não é tão clara, porque o mesmo verbo auxiliar (to be) pode formar passivas verbais e adjetivas. Ou seja: The door was locked é ambígua. Essa sentença pode significar tanto "A porta estava trancada" (passiva adjetiva) como "A porta foi trancada" (passiva verbal) em português. Segundo Borer e Wexler (1987), uma vez que verbos de ação podem ser interpretados como adjetivos derivados de particípio e verbos de não ação não podem, a criança compreenderia 
e produziria mais cedo passivas verbais com verbos de ação, pois estaria, na verdade, compreendendo a estrutura como uma passiva adjetiva (aqui voltamos ao efeito Maratsos, a aquisição tardia de passivas verbais com verbos de não ação). Da passiva verbal com o verbo de ação estragar em (2a) abaixo, a criança pode interpretar (2b), interpretando, assim, o particípio "estragado" como adjetivo. Da passiva verbal com o verbo de não ação ver em (3a) a criança não pode interpretar (3b); não conseguindo interpretar a passiva (3a) como adjetival, a criança tem dificuldade em compreendê-la.

(2) a) O brinquedo foi estragado (pelo menino).

b) O brinquedo estragado.

(3) a) O gato foi visto (por Maria).

b) ${ }^{\star} \mathrm{O}$ gato visto.

A fim de comprovar a hipótese maturacional, Borer e Wexler (1987) conduziram um experimento com crianças adquirindo o inglês e com crianças adquirindo hebraico. Segundo o resultado do estudo, em ambas as línguas a aquisição das passivas adjetivas e das passivas verbais truncadas (sem o agente da passiva explícito) se dá antes da aquisição de passivas verbais. Ainda, os dados do estudo sugerem que as passivas com verbos que denotam ação são adquiridas antes de passivas com verbos que denotam não ação. Essas últimas são adquiridas tardiamente, após os seis anos de idade. Borer e Wexler (1987) concluem que a operação que gera passivas adjetivais amadurece antes da operação que gera passivas verbais (a formação de cadeias-A).

\subsection{CONTRA A HIPÓTESE DA MATURAÇÃO LINGUÍSTICA DE BORER E WEXLER: DÉFICIT DA TRANSFERÊNCIA DO PAPEL TEMÁTICO PARA O SINTAGMA PREPOSICIONADO}

Ainda no âmbito dos princípios inatos da aquisição da linguagem como características universais, Fox e Grodzinsky (1998) acreditam que a criança não tem problema com a formação de cadeias-A, mas com a transferência de papel temático para o sintagma preposicionado (by-phrase) quando esse não é agentivo. Vejamos a estrutura das sentenças passivas em (4).

(4) a) A mulher ouve a música.

a') A música é ouvida pela mulher.

b) O menino chuta a bola.

b’) A bola é chutada pelo menino.

Nas sentenças passivas verbais, como as em (4a') e (4b'), os sintagmas preposicionados (SPs) "pela mulher" e "pelo menino" são o agente da passiva. O agente da passiva tem sempre um papel semântico na frase, seja de agente, experienciador, estímulo, etc. Em (4a), ouvir seleciona um argumento interno (que vira sujeito na voz passiva) com o papel semântico de estímulo ("a música") e um argumento externo (que vira o SP agente da passiva) que tem papel temático de experienciador (“a mulher”). Em (4b), chutar seleciona um argumento interno com o papel tema ("a bola”) e um argumento externo agente ("o menino”). Há, de acordo com Fox e Grodzinsky (1998), um mecanismo que transfere o papel temático da posição do argumento externo lógico (posição do sujeito) para a posição do SP agente da passiva. Assim, transferir o papel temático de experienciador de [a mulher] da posição de sujeito do verbo ouvir para o SP [pela mulher], agente da passiva, é o que a criança não consegue fazer.

Para Fox e Grodzinsky (1998), esse princípio ainda não está maduro e, por isso, as crianças menores de seis anos não compreendem nem produzem passivas de maneira adequada. Ou seja, a transferência do papel temático para o SP ainda não está disponível para crianças muito pequenas; definir o papel semântico do SP agente da passiva é um problema para elas. 
No entanto, há uma ressalva. A partir de evidências de estudos linguísticos anteriores (RAPPAPORT, 1983; JAEGGLI, 1986; GRAMISHAW, 1990, por exemplo), Fox e Grodzinksy (1998) alegam que definir o papel temático do SP só é difícil quando seu papel não é agente, como no caso de (4a'), em que o papel temático do agente da passiva é de experienciador. Por outro lado, em uma sentença passiva como (4b'), "A bola foi chutada pelo menino", em que o SN [o menino] é agente, a criança não teria problema em definir o papel temático de agente do SP correspondente [pelo menino] e compreenderia a frase. Para Fox e Grodzinsky (1998), as crianças produzem outras estruturas com movimento formador de cadeias- $\mathrm{A}^{1}$; por isso, esse princípio já estaria disponível e amadurecido na gramática da criança.

Para sustentar sua hipótese, os autores conduziram um experimento para averiguar qual dos princípios, a transmissão do papel temático ao SP ou a formação de cadeias- $A$, afinal, ainda não está amadurecido nas crianças menores de seis anos. Para isso, procuraram verificar se as crianças têm mesmo algum problema com passivas verbais de verbos de não ação (que possuem cadeiasA) e se não têm problema com as demais passivas truncadas (que possuem cadeias-A, mas não explicitam o SP) e com as passivas adjetivas (que não possuem cadeias-A, mas explicitam o SP).

O experimento consistiu no seguinte: foram apresentadas 24 histórias a treze crianças nativas do inglês, com idades variando entre 3:6 e 5:5. No final de cada história, havia uma sentença que deveria ser julgada como verdadeira ou falsa. As sentenças ativas foram utilizadas como sentenças-controle. Além das sentenças-controle, o experimento tinha seis condições: (1) sentenças passivas com to be com verbos de ação (tanto passivas verbais como passivas adjetivas); (2) sentenças passivas com to get (sem estrutura correspondente em português) com verbos de ação; (3) sentenças passivas com to be com verbos de não ação (passivas verbais); (4) sentenças passivas com to get com verbos de não ação; (5) sentenças passivas com to get com verbos de não ação sem SP (isto é, passivas truncadas); (6) sentenças passivas com to be com verbos de não ação sem SP. Os verbos de ação utilizados no experimento foram touch e chase ("tocar" e "perseguir", respectivamente), e os verbos de não ação utilizados foram hear e see ("ouvir" e "ver"). Seguem os exemplos das sentenças-alvo do experimento, retirados de Fox e Grodzinsky (1998, p. 317)²:

(5) The rock star is being chased by the koala bear. (condição 1)

(6) The boy is getting touched by the magician. (condição 2)

(7) The boy is seen by the horse. (condição 3)

(8) The boy is getting seen by the bear. (condição 4)

(9) The boy is getting seen. (condição 5)

(10) The bear is seen. (condição 6)

(11) The mouse is touching the little girl. (ativa-controle com verbo de ação)

(12) The pizza Baker sees the buffalo. (ativa-controle com verbo de não ação)

\footnotetext{
${ }^{1}$ Fox e Grodzinsky (1998) argumentam que, assumindo Chomsky (1981), sujeitos são gerados dentro do SV (VP-Internal Subjects). Dessa forma, segundo os autores, todas as sentenças do inglês em que o sujeito precede o verbo auxiliar envolvem cadeia-A. No entanto, aceitando a hipótese de que os sujeitos nascem no interior do SV, Borer e Wexler (1992) propuseram um relaxamento da Hipótese Maturacional (Relaxed Maturation Hypotesis - RMH), postulando que as crianças têm dificuldade somente com um tipo de cadeia-A, as cadeias-A que relacionam duas posições temáticas. Contudo, Fox e Grodzinsky (1998) também argumentam que as crianças não têm dificuldade com as passivas-get em inglês que envolvem cadeias-A e têm dificuldade na compreensão de passivas com sujeito pós-verbal em espanhol que não envolvem cadeia-A.

${ }^{2}$ Os exemplos 5, 6, 7, 10, 11 e 12 são retirados diretamente de Fox e Grodzinsky (1998, p. 137). Os exemplos 8 e 9 não constam no trabalho dos autores, mas foram formulados por nós para melhor entendimento das condições do experimento. As traduções (aproximadas) dos exemplos seguem abaixo:

(5) O astro do rock está sendo perseguido pelo urso coala.

(6) O menino está sendo tocado pelo mágico.

(7) O menino é/foi visto pelo cavalo.

(8) O menino está sendo visto pelo urso.

(9) O menino está sendo visto.

(10) O urso é visto.

(11) O rato está encostando na menina.

(12) O padeiro vê o búfalo.
} 
Após ouvir uma história contada pelo experimentador, com o auxílio de bonecos, a tarefa da criança era responder se a última fala de um dos bonecos estava correta ou incorreta (isto é, se era verdadeira ou falsa segundo a história contada). A fala era uma das sentenças passivas-alvo (ou uma frase-controle). Cada tipo de sentença foi colocado tanto em uma história na qual a sentença era verdadeira quanto em uma história na qual a sentença era falsa.

Os resultados mostraram que as crianças acertaram 100\% das sentenças dos tipos (5), (6), (11)e (12), demonstrando comportamento de adultos para lidar com sentenças ativas e passivas com verbo de ação. O desempenho das crianças não foi satisfatório em duas das seis condições: com passivas não truncadas, com verbos de não ação, sentença (7) acima, em que acertaram 46,1\% das sentenças; e com passivas truncadas (sem SP), com verbos de não ação, sentença (10) acima, em que acertaram 86,5\% dos julgamentos.

Os autores não mencionam os resultados das passivas com to get. Para Fox e Grodzinsky (1998), esses resultados servem de argumento contra a hipótese maturacional da formação de cadeias-A, já que indicam que o problema das crianças para compreender passivas não está na formação de cadeias-A em si, mas no processamento correto do SP. Assim, segundo os autores, a sua hipótese do déficit na transmissão do papel temático ao SP explica os resultados do experimento: a dificuldade das crianças de três a cinco anos com as passivas longas com verbo de não ação e a hipótese de maturação linguística de Borer e Wexler (1987) não explicaria esses resultados.

Em suma, Fox e Grodzinsky (1998) propõem que as crianças têm problema com SP não agentivos em passivas. O papel temático de agente pode ser atribuído diretamente pela preposição por $(b y)$, sem necessitar da transmissão do papel temático para o agente da passiva. As crianças possuiriam um módulo de atribuição de papel temático default para as by-phrases, como também já apontara previamente Jaeggli (1986). O papel temático default nas línguas é o de agente. Por isso, as crianças do estudo teriam apresentado dificuldade na compreensão da passiva longa com verbo não agentivo, como a sentença (7), na qual o papel temático do by-phrase é de tema e não de agente.

\section{AQUISIÇÃO GUIADA PELO INPUT LINGUÍSTICO}

\subsection{DEMUTH (1989)}

Outro ponto de vista sobre a aquisição tardia das sentenças passivas propõe que a aquisição não seja de caráter universal, mas que ela varie de acordo com o input que cada comunidade linguística proporciona. Dados de outras línguas que não o inglês e o hebraico demonstram que as crianças compreendem e até mesmo produzem passivas verbais antes dos três anos de idade, incluindo passivas longas, isto é, com by-phrase (DEMUTH, 1989). É o que acontece em algumas línguas bantu, como sesotho, inuktitut e mayan k’iche (cf. ALLEN; GRAGO, 1996; KLINE; DEMUTH, 2010). Em sesotho, não existe passiva adjetiva; portanto, as autoras puderam voltarse mais claramente para a aquisição das passivas verbais. A hipótese da aquisição guiada pelo input é que a frequência dessas construções no entorno linguístico das crianças influencia sua aquisição.

Demuth (1989) apresenta uma pesquisa longitudinal com quatro crianças adquirindo a língua sesotho. Amostras do discurso das crianças foram gravadas e transcritas com a ajuda das avós e das mães. A idade das crianças variou entre 2:1 e 4:1, do início ao final do estudo. O número total de ocorrência de passivas encontradas no discurso das crianças foi de 139 construções. Esses resultados levaram a autora a questionar as hipóteses postuladas sobre a aquisição das sentenças passivas baseadas em inglês e hebraico. Demuth (1989) dividiu a aquisição das passivas do sesotho em três estágios: estágio I (antes de 2:7); estágio II (2:8 a 3:2); e estágio III (3:9 a 4:1). Os dados demonstraram que as crianças falantes de sesotho, até os 2:8, já produzem passivas verbais e as compreendem ainda antes. Segundo a autora, se a hipótese maturacional de Borer e Wexler (1987) está correta, então o princípio gramatical que governa a formação da passiva verbal tem de amadurecer nas crianças falantes de sesotho até a idade de 2:8.

As passivas truncadas são consideradas mais "básicas" do que as passivas longas, aquelas que contêm um by-phrase. Passivas longas vão ser produtivas no discurso das crianças nativas do inglês somente em torno dos dez anos de idade. No entanto, os dados do sesotho mostram um cenário diferente: passivas longas foram 39\% das sentenças passivas produzidas pelas crianças no estágio I; 
25\% no estágio II; e 15\% no estágio III. Com o uso decrescente de passivas longas, o sesotho fornece evidências contrárias para o postulado de que passivas longas são gramaticalmente mais difíceis de aprender do que passivas truncadas. Ainda, o estudo traz exemplos de diálogos entre crianças e adultos em que, em enunciados consecutivos, as crianças passam de passivas longas para passivas truncadas e vice-versa. Isso, segundo a autora, é outra evidência de que as duas formas são acessíveis para as crianças falantes de sesotho. Esses argumentos vão contra a hipótese de déficit na transferência do papel temático para o sintagma preposicionado de Fox e Grodzinsky (1998).

Já em relação ao uso de verbos de não ação em passivas verbais, Demuth (1989) sugere que o uso de passivas com verbos de não ação, tanto em inglês quanto em sesotho, seja mais comum em tipos específicos de discursos e em gêneros textuais do que na fala do dia a dia. Por isso, passivas com verbos de não ação são menos utilizadas pelas crianças do que passivas com verbos de ação. Em conclusão, Demuth (1989) aponta problemas para a hipótese maturacional e indica explicações alternativas para a aquisição das passivas verbais. Primeiramente, a aquisição tardia de passivas verbais em inglês e em hebraico pode ser explicada por outros fatores envolvidos na aquisição da linguagem, que não apenas fatores relacionados à "maturação de princípios sintáticos". Construções gramaticais que geram cadeias-A aparecem mais tarde em hebraico e inglês, o que indica que a formação de cadeia-A está disponível, mas ainda não está ativada nessas línguas (possivelmente, segundo a autora, por questões de opacidade morfofonológica). Pode ainda ser o caso de que a formação de cadeias-A não seja um princípio que amadurece, mas um fenômeno gramatical, um parâmetro da língua, que é aprendido com base nas especificidades de cada língua: "A crescente conscientização das crianças das propriedades tipológicas específicas da sua língua parece ser crucial para o desenvolvimento de passivas verbais” (DEMUTH, 1989, p. 67).

As sentenças passivas têm diferentes papéis nas gramáticas das línguas. Por exemplo, as línguas sotho (sesotho, setswana e spedi) têm uma restrição sobre a topicalização do sujeito. Por isso, as palavras qu não podem ocupar a posição de sujeito das sentenças dessas línguas, por exemplo. Desse modo, as passivas ocupam um papel importante na gramática do sesotho, o de questionar o sujeito ou responder questões sobre o sujeito, como podemos ver no exemplo abaixo, de Demuth (1989, p. 68):

$$
\begin{aligned}
& \text { (13) a) Lijo li-phen-il-o-e ke mang? } \\
& \text { comida sm-cozinhar-prf-PASS-m por quem } \\
& \text { 'A comida foi cozinhada por quem?' }
\end{aligned}
$$

b) Li-phen-il-o-e ke Thabo.

sm-cozinhar-prf-PASS-m por Thabo.

'Foi cozinhada por Thabo'

Essa questão funcional contribuiria para a aquisição rápida das passivas pelas crianças aprendizes de sesotho; entretanto, segundo Demuth (1989), o fator funcional não é o único a operar na aquisição. Por ter um papel funcional importante na gramática, os adultos também utilizam as passivas mais frequentemente: $6 \%$ dos enunciados dos adultos falando com as crianças gravadas pela autora eram sentenças passivas. Em hebraico, até mesmo na fala de adultos, que, presume-se, já têm os princípios que governam a formação das cadeias-A amadurecidos, é raro encontrar o uso de passivas verbais, pois as topicalizações e os sujeitos impessoais desempenham o papel que as sentenças passivas têm em outras línguas. Em hebraico, passivas verbais são mais frequentemente encontradas em textos escritos. Assim, Demuth (1989) sugere que os papéis que as passivas desempenham nas gramáticas das línguas e, consequentemente, a sua frequência de uso fornecem um diagnóstico para prever quando as passivas serão adquiridas em cada língua.

\subsection{DEMUTH ET AL. (2010)}

Um estudo experimental de Demuth et al. (2010) também traz evidências de que crianças de três anos falantes de sesotho compreendem, produzem e generalizam passivas verbais. As autoras conduziram três experimentos: um de compreensão de 
sentenças, um de produção de sentenças e um de generalização de verbos inventados. Eles foram aplicados a dezesseis crianças e dez adultos falantes de sesotho.

No primeiro experimento do estudo, de compreensão, o objetivo foi investigar a compreensão de sentenças ativas e passivas de verbos de ação e de não ação em uma tarefa de identificação de imagem. As crianças tinham de escolher a imagem que correspondia ao áudio, que era composto por sentenças ativas e passivas que descreviam corretamente uma figura. Como esperado, as crianças compreenderam os dois tipos de passivas, com verbos de ação e de não ação. No entanto, as crianças foram significativamente mais bem sucedidas na compreensão de figuras que representavam verbos de ação, acertando 82\% na escolha das imagens, quando comparadas a figuras de verbos de não ação, das quais acertaram $73 \%$. Na comparação entre o desempenho de crianças e adultos, as autoras perceberam que os adultos também foram melhores em identificar as imagens dos verbos de ação ( $99 \%$ ) do que as imagens dos verbos de não ação (89\%). Por isso, as autoras concluíram que o problema está na tarefa de identificação de imagens, pois as imagens para alguns verbos de não ação não são tão claras.

No segundo experimento, de produção de sentenças ativas e passivas, o objetivo era determinar se crianças com três anos eram capazes de produzir sentenças passivas longas (com by-phrase) em uma tarefa de descrição de imagem. Para incitar a produção da passiva, a pesquisadora perguntava "O que está acontecendo com o garoto?", quando o garoto era o paciente da ação. Se a criança respondesse com uma passiva truncada (sem mencionar o agente da passiva), o pesquisador insistia "Me diga toda a frase", para verificar se a criança era capaz de produzir a passiva longa. Em uma situação em que a pergunta e a imagem eram sobre o paciente da ação, as crianças produziram 98\% de passivas e, em situações que incitavam a estrutura ativa, as crianças produziram $95 \%$ de sentenças ativas. Isso demonstra que elas são igualmente capazes de produzir ativas e passivas. Além disso, segundo as autoras, esses resultados demonstram não só a competência sintática das crianças para a produção de ambas as estruturas, mas também a sua competência discursiva para perceber o contexto comunicativo apropriado para utilizar sentenças ativas e passivas. Outro resultado desse segundo experimento foi a produção de sentenças ativas completas em $77 \%$ das produções, e a produção de passivas completas em 25\% das produções de passivas. Em uma segunda rodada do experimento, na qual o pesquisador não podia ver a figura e pedia para a criança falar toda a sentença, a produção de formas completas aumentou: 91\% para ativas e 71\% para passivas. Esse resultado reforça que as crianças são capazes de produzir ambas as estruturas e atentam para as nuances discursivas do seu uso, pois já que o pesquisador não estava vendo a imagem, elas identificaram mais relevância em mencionar quem estava participando da cena apresentada.

O objetivo do terceiro experimento foi verificar se as crianças demonstravam a habilidade de usar verbos novos em um novo frame sintático. Se elas forem capazes disso, tem-se uma evidência de que as representações gramaticais das crianças são abstratas. A evidência de que a gramática das crianças falantes de sesotho é abstrata o suficiente para generalizar a alternância ativa/passiva a verbos novos pode ser a prova mais irrefutável de que elas já possuem o conhecimento gramatical interno de formação de passivas. Logo, as crianças falantes de outras línguas também devem possuir esse conhecimento, baseando-se na premissa da gramática universal como parte da faculdade da linguagem humana. Os resultados desse último experimento comprovaram que as crianças conseguem generalizar a estrutura de sentenças ativas e passivas com verbos inventados. Dado um contexto discursivo focado no paciente, as crianças facilmente generalizaram a forma passiva no uso do novo verbo. Um resultado inusitado foi que, das generalizações passivas, $65 \%$ foram produzidas com o SP, isto é, passivas longas (resultado maior do que o obtido no segundo experimento). As autoras atribuem essa diferença às condições de felicidade para o uso da passiva longa que foram satisfeitas nesse último experimento. Segundo O’Brien et al. (2006), a existência de múltiplos possíveis agentes na cena gera condições propícias para o uso da passiva longa, porque a criança precisa determinar qual personagem, entre os possíveis, está realizando a ação. Como nesse experimento as crianças deveriam brincar com vários bonecos, utilizando os verbos novos, as condições de felicidade para produção de passivas longas foram propícias (nas imagens dos experimentos anteriores, ao contrário, havia apenas dois personagens).

Baseadas nos resultados dos três experimentos, Demuth et al. (2010) chegaram a duas conclusões. A primeira é que, mesmo que certos pré-requisitos maturacionais sejam necessários para a formação das passivas, aspectos específicos do input linguístico são determinantes para a aquisição de sentenças passivas pelas crianças. A frequência de uma estrutura na língua influencia sua aquisição. O uso de frases na voz passiva é mais frequente pelos falantes maduros dessa língua e as crianças são mais expostas a essa estrutura sintática. Além disso, não há ambiguidade morfológica entre as passivas verbais e as adjetivas em sesotho, o que torna a 
estrutura mais transparente para a aquisição. Ou seja, o papel do input linguístico da criança é relevante para a aquisição das sentenças passivas, seja tardia ou não.

Antes de passarmos para a seção dos estudos sobre aquisição de passivas verbais em PB, resumamos as ideias resenhadas aqui, envolvidas nas duas propostas teóricas sobre a aquisição de sentenças passivas, no Quadro 1.

\begin{tabular}{|c|c|c|c|c|c|}
\hline & & \multicolumn{2}{|c|}{ Maturação de princípios } & \multicolumn{2}{|c|}{ Influência do input Linguístico } \\
\hline \multicolumn{2}{|c|}{ Passivas verbais } & $\begin{array}{c}\text { Borer e Wexler } \\
\quad(1987)\end{array}$ & $\begin{array}{l}\text { Fox e Grodzinsky } \\
\end{array}$ & Demuth (1989) & Demuth et al. (2010) \\
\hline \multirow[t]{2}{*}{ Com verbo de ação } & curta & \multirow{2}{*}{$\begin{array}{l}\text { São compreendi- } \\
\qquad \underline{\text { das como }} \\
\text { sentenças } \\
\text { passivas adjetivas } \\
\text { antes dos } 6 \text { anos, } \\
\text { falantes de inglês } \\
\text { e hebraico. }\end{array}$} & $\begin{array}{c}\text { Compreensão_de } 100 \% \\
\text { com 3:6 a 5:5 anos, } \\
\text { falantes de inglês. }\end{array}$ & $\begin{array}{c}\text { Produção aos } 2: 8 \\
\text { anos, falantes de } \\
\text { sesotho. } 61 \% \text { das } \\
\text { passivas } \\
\text { produzidas. }\end{array}$ & $\begin{array}{c}\text { Produção de 29\%; } \\
\text { Generalização de 35\%; aos } 3 \\
\text { anos, falantes de sesotho. }\end{array}$ \\
\hline & longa & & $\begin{array}{c}\text { Compreensão de } 100 \% \\
\text { com 3:6 a 5:5 anos. }\end{array}$ & $\begin{array}{c}39 \% \text { das passivas } \\
\text { produzidas. }\end{array}$ & $\begin{array}{l}\text { Compreensão de } 82 \% \text {; } \\
\text { Produção de } 71 \% \text {; } \\
\text { Generalização de } 65 \% \text { com } \\
\text { verbos novos. }\end{array}$ \\
\hline \multirow{2}{*}{$\begin{array}{l}\text { Com verbo de não- } \\
\text { ação }\end{array}$} & curta & \multirow{2}{*}{$\begin{array}{c}\text { Não são } \\
\text { compreendi-das } \\
\text { antes dos } 6 \text { anos } \\
\text { em inglês e em } \\
\text { hebraico. }\end{array}$} & $\begin{array}{c}\text { Compreensão de } 86,5 \% \\
\text { com 3:6 a 5:5 anos. }\end{array}$ & $\begin{array}{c}\text { Produção aos 2:8 } \\
\text { anos. }\end{array}$ & Não testado neste estudo. \\
\hline & longa & & $\begin{array}{c}\text { Compreensão de } 46,1 \% \\
\text { com 3:6 a 5:5 anos. }\end{array}$ & $\begin{array}{c}\text { Produção aos 2:8 } \\
\text { anos. }\end{array}$ & Compreensão de $73 \%$. \\
\hline
\end{tabular}

Quadro 1: Estudos clássicos sobre a aquisição de passivas

Fonte: Elaborado pelos autores.

Vemos, no quadro acima, que o atraso na aquisição de passivas verbais é questionável. As crianças falantes do sesotho compreendem passivas verbais longas e curtas aos 2:8 anos. Entretanto, vemos também que a compreensão de passivas verbais com verbos de não ação é sempre mais difícil para todas as crianças, sejam elas falantes de inglês, hebraico ou sesotho. Em relação à produção, Demuth (1989) também menciona que a produção de passivas com verbos de não ação foi menor do que a produção de passivas com verbos de ação.

As sentenças passivas longas não são, segundo os estudos da proposta teórica da influência do input linguístico, gramaticalmente mais difíceis que as passivas curtas, como propõem Fox e Grodzinsky (1998). Aqui, Demuth et al. (2010) retornam à importância do design do experimento. Com uma tarefa que tenha múltiplos personagens, não somente dois, e na qual o pesquisador não esteja enxergando o vídeo ou a história contada pela criança, as crianças produzem passivas longas, dada a relevância discursiva de se mencionar, para o pesquisador, o agente da passiva.

Vemos que a Hipótese de Maturação de habilidades linguísticas se apoia na não compreensão das passivas com verbos de não ação para a sustentação de sua proposta, o que parece ser um dado constante em todos os experimentos. No entanto, as questões metodológicas levantadas pelo estudo de Demuth et al. (2010) parecem desvendar o mistério da não produção de sentenças passivas longas, como vimos, e também parecem trazer dados que corroboram os postulados de Demuth (1989). Em Demuth et al. (2010), as crianças compreenderam sentenças passivas verbais longas com verbos de não ação, ainda que a compreensão dessa estrutura 
tenha sido claramente mais difícil para as crianças (73\% para passivas longas com verbos de não ação e $82 \%$ para passivas longas com verbos de ação). Com esses dados em mente, vejamos como os estudos do PB podem contribuir para nossa discussão.

\section{AQUISIÇÃO DE PASSIVAS EM PB}

O primeiro estudo sobre aquisição de sentenças passivas no Brasil foi o de Perotino (1995). A autora investigou a produção espontânea de passivas na fala de uma criança com seus pais, gravando a interação entre eles durante três anos, totalizando sessenta horas de gravação, no período de três a cinco anos de idade. O resultado é surpreendente: a autora não encontrou nenhuma passiva na fala da criança nem na fala dos pais. A conclusão é de que a baixa frequência dessa estrutura nos dados se dá porque sentenças passivas são mais representativas na modalidade escrita do que na fala em português brasileiro (cf. PEROTINO, 1995).

\subsection{EXPERIMENTO DE PRODUÇÃO: GABRIEL (2001)}

Gabriel (2001) fez um estudo comparativo sobre aquisição de passivas em inglês e em PB. A autora desenvolveu dois tipos de experimentos: produção e compreensão de passivas, em ambas as línguas. Ao conduzir seus experimentos com crianças de quatro faixas etárias (três a quatro; cinco a seis; sete a oito; e nove a dez anos) e também com um grupo controle de adultos, Gabriel (2001) traz um bom panorama da aquisição de passivas nas duas línguas estudadas. Vejamos com algum detalhe o experimento de produção de sentenças ativas e passivas em PB.

O experimento de produção foi realizado com 79 crianças e vinte adultos. A tarefa dos participantes era dizer ao pesquisador "o que estava acontecendo", depois de assistirem a um desenho animado. Quando o desenho terminava, com a última cena congelada na tela, o pesquisador apontava para um personagem na tela e solicitava à criança: "Me fala sobre o agente/paciente". Esse vídeo continha doze cenas, divididas em quatro condições: cena simples, com um evento (O leão empurra o urso) x cena complexa, com dois eventos (A cobra morde o cavalo, então a cobra morde a ovelha); cena com o agente topicalizado (A menina beija o menino) $\mathrm{x}$ cena com o não agente ${ }^{3}$ topicalizado (A menina foi beijada pelo menino). Todas as cenas apareceram uma vez na condição "agente topicalizado" e uma vez na condição "não agente topicalizado", totalizando 24 julgamentos. A autora esperava que os participantes descrevessem o evento expresso na cena em que o agente era topicalizado com uma sentença ativa e que utilizassem uma sentença passiva quando o não agente fosse estabelecido como tópico da cena.

Uma constatação de Gabriel (2001), baseada no experimento modelo de Marchman et al. (1991), é a de que a produção de passivas é mais frequente com cenas prototipicamente transitivas. A autora classificou as cenas em prototipicamente transitivas de acordo com o quadro dos "Componentes de Transitividade" de Hopper e Thompson (1980). Todas as cenas tinham três participantes animados aparecendo na tela, uma ação em que o "agente" era altamente potente e o "objeto" era afetado.

Todos os participantes produziram sentenças ativas nas cenas que deveriam descrever o que estava acontecendo com o agente; por isso, a autora concluiu que "[...] a construção ativa, incluindo suas características sintáticas, semânticas e pragmáticas, parece estar completamente desenvolvida em falantes do PB antes do seu terceiro aniversário” (GABRIEL, 2001, p. 90).

Na condição em que a pesquisadora solicitava "Me fala sobre o 'não agente”, as construções denominadas "não passivas" pela autora ultrapassaram 50\% das respostas das crianças e chegaram a 45\% das respostas dos adultos. O grupo das crianças mais novas, de três a quatro anos, respondeu 39\% de sentenças ativas, $7 \%$ de passivas e $52 \%$ de não passivas. O grupo de cinco a seis anos teve um número maior de respostas passivas, $11 \%$. O que se pode notar nos resultados foi que as respostas ativas para as situações de não agente topicalizado diminuem nos grupos de crianças mais velhas. Ao mesmo tempo, o uso de passivas aumenta, chegando a 55\% nos adultos. As respostas "não passivas", que são as demais estratégias usadas pelos grupos para responder à situação do não agente topicalizado, foram divididas pela autora em quatro respostas:

${ }^{3}$ Gabriel (2001) utiliza o termo "não agente" para se referir ao participante afetado pelo evento em uma estrutura passiva. 
(14) Respostas não passivas (cf. GABRIEL, 2001, p. 50):

a) não evento. Ex.: O urso gosta do tigre.

b) descrição do evento. Ex.: O urso deixou o tigre lamber ele.

c) duas orações. Ex.: O tigre tava só sentado ali E daí o urso lambeu ele.

d) clivagem. Ex.: Foi o tigre que o urso lambeu.

Gabriel (2001) concluiu que, com o passar do tempo, assim como diminuem as respostas ativas, as crianças também vão deixando de utilizar respostas "não evento" como (14a). Observando as três construções restantes, que cumprem com o papel discursivo de topicalizar o não agente e de realizar a tarefa proposta no experimento, nota-se que, no último grupo de crianças, de nove a dez anos, e no grupo de adultos, a descrição do evento (14b) é a estratégia mais utilizada quando se excluem as respostas passivas, seguida do uso de duas orações (14c) e, por último, da clivagem (14d).

No que diz respeito à produção de passivas longas ou truncadas, observa-se, nos dados de Gabriel (2001), uma crescente preferência por passivas longas ao longo dos grupos etários. A partir da faixa etária de sete a oito anos, a produção de passivas longas é maior do que a produção de passivas truncadas, alcançando a produção de $91 \%$ nos adultos. Conforme podemos verificar no Gráfico 1 de distribuição das passivas longas ("cheias", na terminologia de Gabriel) e truncadas do PB, as crianças mais novas preferem as truncadas, enquanto as mais velhas e os adultos produzem mais passivas longas, com o agente da passiva expresso na frase (cf. GABRIEL, 2001, p. 97).

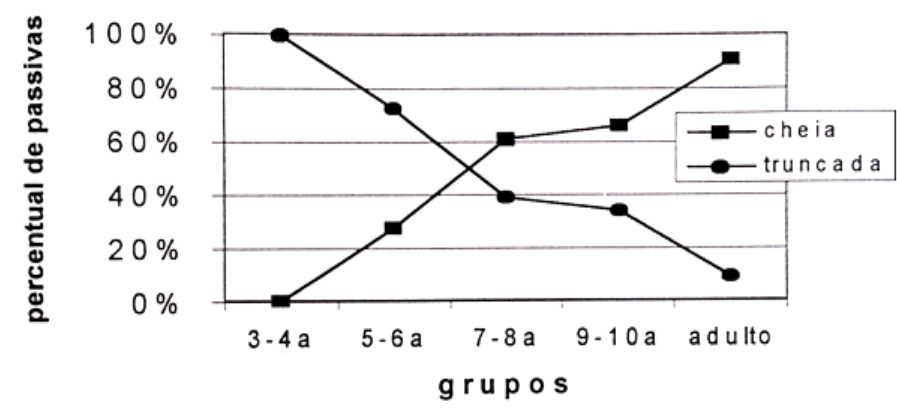

Gráfico 1: Produção de passivas longas e truncadas em PB

Fonte: Gabriel (2001, p. 97).

Estudos de cunho funcionalista (GIVÓN, 1989, por exemplo) apontam para o fato de que a principal função da passiva é promover o elemento "não agente" a uma posição de destaque na estrutura sintática de superfície da frase. Por essa razão, podemos omitir o agente da passiva. Seguindo esse raciocínio, Gabriel (2001) analisou se as crianças eram sensíveis à função discursiva do agente da passiva. A autora observou que as passivas que traziam expresso o agente da passiva foram mais produzidas em cenas complexas, que tinham dois eventos, do que em cenas simples, com apenas um evento (resultados semelhantes aos encontrados mais tarde por O’Brien et al. (2006) e Demuth et al. (2010)). Isso indica que as crianças tendem a usar o agente da passiva quando ele é apropriado e relevante ao contexto discursivo.

Para cumprir a função discursiva de promover o não agente, os participantes do experimento de Gabriel (2001) utilizaram outras estratégias além da estrutura passiva, como mostramos em (14). Nas respostas codificadas como "descrição do evento" (14b), notouse que os participantes usaram um conjunto de verbos que permite que o não agente ocupe a posição de sujeito, sem estar na voz passiva, como ganhar, levar, receber, sofrer, tomar, deixar, pegar, sentir. Esses verbos satisfazem o contexto discursivo da promoção do não agente a tópico frasal/sujeito sem que uma construção passiva seja usada.

Comparando os dados do estudo de produção do PB e do inglês, os verbos experienciais e dativos parecem ser mais frequentes em português do que em inglês. Abaixo vemos exemplos de frases produzidas com esses verbos no experimento de produção de sentenças em PB de Gabriel (2001). 
(15) Descrições do evento com verbos experimentais e dativos:

a) Ela ganhou um beijo do guri.

b) O burro levou um empurrão e o bode não levou nada.

c) O porco recebeu carinho do gambá.

d) O urso tomou uma bolada na bunda.

e) O cavalo deixou a cobra picar ele.

Ainda de acordo com Gabriel (2001), antes da faixa etária entre cinco e seis anos, as crianças não produzem passivas longas. No que diz respeito à compreensão de sentenças passivas, Gabriel (2001) também relata a dificuldade das crianças de compreender essa estrutura nas faixas etárias até os cinco e seis anos de idade. Assumindo uma abordagem teórica conexionista, a autora defende que a dificuldade das crianças nativas do PB se deve à baixa frequência de passivas no input linguístico, isto é, na fala dos adultos brasileiros. Gabriel (2001) reafirma o ponto que vimos em Demuth (1989): a produção e a compreensão de passivas variam entre as línguas devido à saliência dessa estrutura no entorno linguístico da criança ${ }^{4}$.

\subsection{NOVOS EXPERIMENTOS DE COMPREENSÃO DE PASSIVAS: RUBIN $(2006,2009)$}

Rubin (2006) estudou a compreensão de sentenças passivas do PB por crianças brasileiras de seis anos de idade. A autora investigou, através de cinco experimentos, a compreensão de passivas com verbos de ação e verbos de não ação; a compreensão de passivas longas bizarras; e se as crianças teriam a tendência de interpretar o primeiro SN da sentença passiva como agente/causador (interpretando passivas como se fossem ativas).

O primeiro experimento de Rubin $(2006)^{5}$ verificou a compreensão de sentenças passivas longas e curtas com verbos de ação. Segundo Maratsos et al. (1985), as crianças não têm dificuldade em compreender passivas verbais com os verbos de ação. Segundo Fox e Grodzinsky (1998), o SP das passivas longas dificulta a sua compreensão pelas crianças. A tarefa das crianças consistia em representar a sentença que a pesquisadora proferia com bonecos de pelúcia. Os resultados desse experimento mostraram que não há diferença significativa na compreensão de passivas longas e curtas pelas crianças de seis anos participantes do experimento. Ainda segundo os resultados da autora, não há diferença significativa na compreensão de passivas e ativas.

O segundo experimento tinha o objetivo de testar a compreensão de passivas longas e curtas com verbos de ação e de não ação em PB. As crianças tinham de selecionar o desenho correto que representava a frase dita pela pesquisadora. Os resultados da autora mostram que as crianças compreendem passivas longas e curtas com verbos de ação, conforme já corroborado pelo primeiro experimento. No entanto, elas não compreendiam passivas (nem longas nem curtas) com verbo de não ação. Os resultados, segundo a autora, estão ao nível do acaso para a compreensão de passivas truncadas e abaixo do nível do acaso para a compreensão de passivas longas (cf. detalhes em RUBIN, 2006).

\footnotetext{
${ }^{4}$ Contrapondo as conclusões de Gabriel (2001), Menuzzi (2002) atenta para o fato de a autora não ter separado as passivas do inglês em seus diferentes tipos, getpassives e be-passives. Menuzzi (2002) argumenta, ainda, que, quando divididas em diferentes grupos, as be-passives do inglês e as passivas-ser do português (ambas passivas verbais) demonstram o mesmo padrão de aquisição pelas crianças das faixas etárias de três a seis anos de idade. Dessa maneira, Menuzzi propõe que os resultados da autora não comprovam as ideias de Demuth (1989); antes, parecem aproximar-se dos resultados de Borer e Wexler (1987), devido à dificuldade das crianças com as estruturas das passivas do tipo be-passives, passivas verbais, e não com as passivas do tipo get-passives.
}

${ }^{5}$ Falaremos sobre três experimentos de Rubin. Remetemos o leitor a Rubin (2006) para os demais experimentos. 
Para Rubin (2006), dizer que as crianças não compreendem sentenças passivas é dizer que elas as interpretam como sentenças ativas. A identidade estrutural de ambas as estruturas facilita tal interpretação. A autora se baseia na explicação minimalista de Boeckx (1998) para quem, até certo ponto da derivação, ativa e passiva apresentam a mesma estrutura. Para Rubin (2006), a dificuldade das crianças com a passiva reside no fato de que, ao ouvir uma sentença passiva, elas interpretam o primeiro SN como agente/causador da ação e o segundo SN como paciente/tema.

Em um terceiro experimento, Rubin (2006) procurou verificar, com outra tarefa, se as crianças interpretavam o primeiro SN de uma passiva longa como agente/causador, através de perguntas feitas sobre o agente/causador da ação de uma passiva. Foram testadas passivas reversíveis e não reversíveis. Nesse experimento, a pesquisadora dizia uma sentença duas vezes e fazia uma pergunta sobre o agente/causador da ação. O exemplo da autora é o seguinte: “A menina foi esfregada pela mãe”, e a pergunta feita para a criança era "Quem esfregou?". Nesse experimento, os resultados foram diferentes para as sentenças passivas reversíveis e não reversíveis, o que não tinha acontecido nos experimentos anteriores. As crianças parecem saber que nas passivas não reversíveis o agente não é o primeiro SN da frase; contudo, no que diz respeito às passivas reversíveis, as respostas corretas estão um pouco acima do nível do acaso, o que mostra, segundo a autora, que elas ainda não têm absoluta certeza de como interpretar o primeiro SN de uma sentença passiva reversível. Segundo Rubin (2006), os resultados obtidos na interpretação de passivas longas reversíveis sustentam a hipótese de que, em um período anterior à compreensão das passivas, ou pelo menos no período em que a compreensão de passivas ainda é instável, a criança parece interpretar o primeiro SN de uma passiva longa como o agente/causador da ação.

Em síntese, os experimentos de Rubin (2006) mostram que as crianças de seis anos falantes do PB compreendem passivas longas, reversíveis e não reversíveis, com verbo de ação, e que elas não compreendem de maneira satisfatória as passivas com verbo de não ação. Contudo, como o desempenho das crianças em distinguir passivas reversíveis longas semanticamente boas de passivas bizarras e em distinguir passiva longa (reversível e não reversível) de ativa é baixo, a autora conclui que a passiva longa ainda não está completamente adquirida pelas crianças de seis anos falantes do PB.

Posteriormente, Rubin (2009) decidiu refazer experimentos de compreensão com crianças mais novas, dessa vez, com crianças de três e quatro anos. Ali a autora apresenta duas tarefas com 48 crianças falantes nativas do PB, com idades entre três e 4:11. A primeira tarefa buscou testar a compreensão de passivas longas e de suas ativas correspondentes. A segunda tarefa buscou testar a compreensão de passivas truncadas. Ambas as tarefas continham somente verbos de ação. Na primeira tarefa, a investigadora falava a sentença e a criança tinha de representar o conteúdo da sentença com bonecos. Na segunda tarefa, a criança ouvia uma sentença dita pela pesquisadora e tinha de escolher, entre duas imagens, qual representava a sentença dita.

Os resultados de Rubin (2009) mostram que 47,91\% das crianças testadas não compreenderam as sentenças passivas longas e somente $16,66 \%$ das crianças não compreenderam as passivas truncadas. A autora fez análises em grupo, mas decidiu fazer análises individuais também, por acreditar que talvez as análises em grupo pudessem mascarar resultados. Ela analisou separadamente as crianças que estavam abaixo do nível do acaso na interpretação de passivas longas e concluiu que essas crianças trocam os papéis temáticos dos SNs, interpretando o SN de uma sentença passiva como o agente/causador da ação e o segundo SN como paciente da ação, segundo a ordem linear de uma sentença ativa, em que temos, via de regra, $\mathrm{SN}_{\text {sujeitolagente }} \mathrm{V} \mathrm{SN}_{\text {objetolpaciente. }}$

\subsection{NOVOS EXPERIMENTOS DE COMPREENSÃO DE PASSIVAS: LIMA JÚNIOR (2012)}

Os experimentos de compreensão de Lima Júnior (2012) tiveram o objetivo de testar aspectos sintáticos e semânticos das sentenças passivas em PB. Três experimentos foram conduzidos, todos de compreensão. O primeiro foi uma réplica do experimento de Fox e Grodzinsky (1998), com melhoras no design experimental, como o aumento do número de participantes e do número de verbos testados. O objetivo era testar os aspectos relacionados às principais hipóteses sobre a aquisição das passivas: o tipo de passiva, curta e longa, e o tipo de verbo, de ação e de não ação. Lima Júnior (2012) pretendia averiguar se a presença do SP dificultava a compreensão e se as passivas com verbos de ação seriam mais fáceis de compreender, fossem elas longas ou curtas. 
O primeiro experimento contou com 24 crianças. A média de idade das crianças era de 5:6. O teste também contou com um grupo controle de 24 adultos. O experimento seguiu o modelo de Fox e Grodzinsky (1998), de julgamento de verdade, e utilizou três bonecos para a manipulação das cenas das histórias contadas. A tarefa das crianças era mostrar uma carinha feliz ou uma carinha triste para o fantoche que dizia uma frase sobre a história ao final dela. As crianças deveriam mostrar a carinha feliz se essa sentença fosse compatível com os eventos da história ou a carinha triste, caso a sentença não fosse compatível. Os resultados do experimento atestaram a facilidade das crianças em compreender as passivas truncadas agentivas ditas pelo fantoche. A dificuldade das crianças com as passivas longas agentivas, se comparadas às truncadas agentivas, contraria a hipótese de Fox e Grodzinsky (1998), que afirmavam que passivas longas agentivas não seriam um problema para as crianças devido à possível atribuição do papel temático de agente para o SN contido no SP. Para Lima Júnior (2012), o panorama que se delineou nos seus resultados foi de que o processamento do SP é um fator de custo adicional no processamento de sentenças passivas.

Os resultados do primeiro experimento conduziram ao design do segundo e do terceiro experimentos de compreensão. Observando a facilidade de compreensão das passivas truncadas agentivas, o autor pensou que isso seria um indício de que as crianças estariam atribuindo uma leitura de passiva adjetiva a essas estruturas, como acontece em inglês (cf. BORER; WEXLER, 1987). Essa leitura adjetiva só seria possível se os particípios dos verbos de ação estivessem recebendo uma leitura resultativa, segundo o autor. No entanto, para atribuir essa leitura resultativa aos particípios dos verbos principais da sentença, as crianças não estariam se valendo da distinção codificada nos verbos auxiliares ser (passiva verbal) e estar/ficar (passiva adjetival) em português. Por isso, seu segundo experimento buscou identificar se o traço semântico de afetação do SN era o que licenciava a leitura resultativa adjetiva e, assim, facilitava a compreensão das passivas como passivas adjetivas. Esse experimento foi feito unicamente com verbos psicológicos, que foram divididos em dois grupos: um que traz verbos que não provocam mudança de estado no SN sujeito (admirar, ver, ouvir: "O João foi visto (pelo Pedro)", em que o sujeito não é afetado e, por isso, o particípio não pode ser entendido como um adjetivo); e outro grupo com verbos psicológicos que provocam mudança de estado no sujeito (assustar, irritar, magoar: "O Pedro foi assustado (pelo João)”). Para Lima Júnior (2012, p. 143-4), “[...] a ausência do traço de afetação deixaria a criança em dúvida quanto à natureza desse particípio, invalidando a leitura adjetival, o que, de certa forma, será essencial para a condução da reanálise e alcançar a aquisição da passiva eventiva”.

Os resultados desse segundo experimento confirmaram as previsões do autor. A impossibilidade de determinar a afetação do SN, que ocorre com o particípio dos verbos ver, ouvir, admirar e respeitar, dificultou a compreensão das passivas com esses verbos. A compreensão de passivas truncadas com os verbos psicológicos que admitem traço de afetação (como assustar) foi tão boa quanto a compreensão das passivas truncadas com verbos de ação no primeiro experimento. Isso parece indicar que a leitura adjetival está sendo licenciada pelas crianças. Lima Júnior (2012) entendeu que a passiva truncada estava sendo processada como uma construção resultativa pelas crianças - e não eventiva - e isso o aproxima da hipótese de Borer e Wexler (1987) sobre as passivas do inglês.

Em seu último experimento, o autor averiguou a diferença entre os verbos auxiliares para a formação de passivas adjetivas (estar) e para a formação de passivas verbais (ser). A hipótese básica por trás desse experimento era que a distinção entre os verbos auxiliares ser e estar não seria essencial para a compreensão. Se essa hipótese fosse confirmada, haveria mais um argumento para sustentar a ideia de que as passivas truncadas agentivas são licenciadas na gramática das crianças como sentenças adjetivas. 
Para testar essa hipótese, foram apresentados vídeos gravados às crianças. Aparecia uma cena em que um personagem executava uma ação sobre outro personagem e a história podia ter dois finais: a última cena era o resultado da ação desencadeada no vídeo por um dos personagens, ou a última cena que aparecia na tela era um resultado contrário à ação desencadeada pelo personagem agente, graças a alguma outra coisa que havia ocorrido no vídeo. Por exemplo, um rapaz e um menino aparecem no vídeo, o rapaz coloca o menino sentado e o amarra com uma corda. No primeiro final, chamado de "imagem mantida", a última cena era o menino mais novo amarrado. No segundo final, chamado de "imagem não mantida”, o menino mais novo se desamarra e a última cena é o menino sorridente com a corda nas mãos. O experimento tinha cinco condições: duas relacionadas à imagem (mantida x não mantida) e três relacionadas aos auxiliares (foi, está e estava). Na última cena do vídeo, o pesquisador perguntava: "O menino foi amarrado?". Para testar o auxiliar de passivas adjetivas, o pesquisador perguntava tanto no presente quanto no passado "O menino estava amarrado?" e "O menino está amarrado?".

Os resultados mostraram que a leitura adjetival estativa, com o verbo estar (“O menino está amarrado?”), das passivas adjetivas, facilita a sua compreensão pelas crianças, como era de se esperar. As crianças acertaram praticamente $100 \%$ das perguntas com o verbo estar no presente.

No que diz respeito às passivas verbais com o auxiliar ser, constatou-se uma tendência de atribuir uma leitura adjetival resultativa a essas construções. As crianças responderam mais "sim" a sentenças passivas como "A almofada foi para o chão?" se a almofada estivesse no chão na última cena da história vista pela criança. Para essa condição com o verbo ser, a resposta correta era sempre "sim", tanto para a "imagem mantida", quanto para a "imagem não mantida", pois mesmo que o menino se desamarrasse ou a almofada não estivesse mais no chão na última cena, a ação havia de fato ocorrido. Por isso, o grande número de respostas "não" das crianças de acordo com a imagem final é um forte indício, segundo o autor, para se pensar que a criança tem uma interpretação adjetiva resultativa frente às sentenças passivas agentivas curtas: "[... isto corrobora o fato de que a passiva eventiva ainda não teria sido adquirida plenamente pelas crianças até a idade testada" (LIMA JUNIOR, 2012, p. 154).

No entanto, como esse último experimento foi feito com dois grupos de crianças (de 3:9 e de 5:5, em média), foi possível verificar que, conforme as crianças vão ficando mais velhas, elas passam a diferenciar particípios e adjetivos, interpretando a passiva com o auxiliar ser como passiva verbal, identificando particípios como verdadeiros verbos, dotados de uma camada agentiva. O autor conclui que as crianças passam de uma atribuição adjetival (estativa ou resultativa) para a derivação de uma passiva verbal. Por volta dos cinco anos, já seriam capazes de reconhecer e derivar certas estruturas passivas, desde que a leitura adjetival seja possível. As sentenças passivas truncadas agentivas estariam sendo interpretadas como passivas adjetivas também em português, como foi postulado para as passivas compreendidas em tenra idade pelas crianças falantes de inglês (BORER; WEXLER, 1987). Dessa maneira, o autor afirma que seu estudo parece indicar que a aquisição de passivas é uma aquisição dos diferentes particípios da língua e que questões maturacionais estão em jogo nesse processo de aquisição.

Nesta seção, trouxemos alguns estudos sobre a aquisição de sentenças passivas em PB. Os estudos de Gabriel (2001), Rubin (2006, 2009) e Lima Júnior (2012) parecem coincidir em alguns resultados. As crianças, em torno dos três anos, já compreendem bem sentenças ativas, mas, pelo menos até os quatro anos, elas parecem interpretar sentenças passivas longas como sentenças ativas (RUBIN, 2006, 2009). Passivas truncadas agentivas, isto é, com verbos de ação, são compreendidas já por crianças de três e quatro anos, e passivas longas com verbos de ação são compreendidas pelas crianças aos cinco e seis anos de idade. Contudo, aos seis anos as crianças ainda têm um conhecimento instável acerca de sentenças passivas longas, não compreendendo as passivas com verbo de não ação e não conseguindo diferenciar, por exemplo, passivas semanticamente boas de passivas bizarras (RUBIN, 2006). O trabalho mais recente em PB que resenhamos, o de Lima Júnior (2012), parece levar em conta os dados dos trabalhos anteriores para a elaboração de seus experimentos. Ao final, Lima Júnior (2012) conclui que seus dados corroboram a teoria de Borer e Wexler (1987) de que as passivas truncadas agentivas do PB são interpretadas como passivas adjetivas, como em inglês. O efeito Maratsos de aquisição tardia de sentenças passivas com verbos de não ação parece se confirmar em todos os estudos de aquisição de passivas em PB que apresentamos aqui. Podemos ver a compilação dos dados destes estudos no quadro seguinte: 


\begin{tabular}{|c|c|c|c|c|c|}
\hline & & Gabriel (2001) & Rubin (2006) & Rubin (2009) & Lima Júnior (2012) \\
\hline Passivas & bais & $\begin{array}{c}\text { Produção } \\
\text { Idades: } 3 \text { a 4; } 5 \text { a 6; } 7 \text { a 8; } 9\end{array}$ & Compreensão & Compreensão Idade: 3 a & Compreensão \\
\hline $\begin{array}{l}\text { Com verbo } \\
\text { de ação }\end{array}$ & curta & $\begin{array}{c}3 \text { a } 4: 7 \% \\
5 \text { a 6: } 11 \% \text { de passivas, } \\
72 \% \text { curtas } \\
7 \text { a } 8: 33 \% \text { de passivas, } \\
39 \% \text { curtas } \\
\text { 9 a 10: } 29 \% \text { de passivas, } \\
35 \% \text { curtas }\end{array}$ & $\begin{array}{c}\text { Compreendem quase } \\
100 \%\end{array}$ & Compreendem 83,34\% & Compreendem $87,50 \%$ \\
\hline & longa & $\begin{array}{c}3 \text { a } 4: 0 \% \\
5 \text { a } 6: 28 \% \\
7 \text { a } 8: 61 \% \\
9 \text { a } 10: 65 \%\end{array}$ & $\begin{array}{c}\text { Compreendem quase } \\
100 \%\end{array}$ & Compreendem 50,09\% & Compreendem 66,75\% \\
\hline & curta & Não testado & Não compreendem & Não testado & Compreendem 66,75\% \\
\hline & longa & Não testado & Não compreendem & Não testado & Compreendem $43,75 \%$ \\
\hline
\end{tabular}

Quadro 2: Estudos de aquisição de passivas verbais em PB

Fonte: Elaborado pelos autores.

\section{CONSIDERAÇÕES FINAIS: EVIDÊNCIAS PARA A HIPÓTESE MATURACIONAL}

Neste artigo, procuramos discutir, através de dados de estudos clássicos e recentes, a aquisição tardia de sentenças passivas, com alguma atenção especial à contribuição de estudos sobre aquisição de passivas em PB. Como vimos, duas hipóteses são defendidas na literatura sobre o assunto: a hipótese maturacional e a hipótese de influência direta do input linguístico. Ao observarmos com atenção o Quadro 2, percebemos que os estudos em PB parecem indicar que a hipótese maturacional fornece uma explicação mais acurada para os dados da nossa língua. Dos dados dos estudos clássicos e dos dados dos estudos do PB que resenhamos aqui, extraímos a ideia de um continuum na aquisição de estruturas passivas.

Ativas $\rightarrow$ Passivas curtas com verbos de ação $\rightarrow$ Passivas longas com verbos de ação $\rightarrow$ Passivas curtas e longas com verbos de não ação

Todos os estudos do PB que resenhamos aqui mostraram que as crianças, aos três anos, compreendem 100\% e produzem sentenças ativas. As sentenças ativas do $\mathrm{PB}$ são adquiridas primeiro e, por isso, ocupam o primeiro lugar no continuum de aquisição. Outra generalização que podemos extrair dos estudos sobre aquisição de passivas em PB é que as crianças têm mais facilidade em compreender sentenças passivas curtas com verbos de ação. Essa facilidade se deve ao fato de que as crianças estão interpretando as passivas agentivas curtas como sentenças passivas adjetivas, tal como propuseram Borer e Wexler (1987). Lima Júnior (2012) mostra que passivas truncadas com verbos de não ação, por exemplo, as sentenças com verbos psicológicos sem traço de afetação, não são compreendidas pelas crianças porque não é possível fazer uma leitura adjetival de tais estruturas. A não maturação de cadeias-A parece explicar a produção e compreensão de passivas truncadas por crianças de três a quatro anos falantes do PB, já que são 
compreendidas como passivas adjetivas. Tanto os estudos em PB, como também os demais trabalhos que resenhamos, corroboram o fato de que crianças com três e quatro anos de idade compreendem e/ou produzem passivas truncadas com verbos de ação.

As passivas longas com verbos de ação ocupam o terceiro lugar em nosso continuum: as crianças começam a compreender as passivas em torno dos cinco e seis anos de idade. No experimento de produção de Gabriel (2001), as crianças só começam a produzir significativamente passivas longas na faixa etária dos sete aos oito anos. Assim, aos seis anos, as crianças parecem compreender passivas longas com verbos de ação, ainda que este conhecimento seja um pouco instável e vá se consolidar em torno dos sete e oito anos em PB.

As passivas verbais, tanto curtas como longas, com verbos de não ação, ocupam o quarto e último lugar no continuum de aquisição de estruturas passivas. Todos os estudos que apresentamos demonstram a maior dificuldade das crianças na compreensão e produção de sentenças passivas com verbos de não ação. Nos estudos do PB que levaram em conta verbos de não ação (RUBIN, 2006; LIMA JÚNIOR, 2012), esse tipo de construção parece não estar estável nem aos seis anos. Nesse sentido, dados do inglês, do hebraico e do PB parecem constatar o efeito Maratsos, a aquisição tardia de sentenças passivas com verbos de não ação.

Não podemos concluir sem fazer uma ressalva. Os dados do sesotho divergem da conclusão a que chegamos. Crianças falantes de sesotho, aos três anos, não só compreendem, como produzem e generalizam com verbos novos inventados as construções passivas. A compreensão de sentenças passivas longas com verbos de não ação parece ser mais difícil, como o é para as crianças falantes de outras línguas. No entanto, é, ainda, consideravelmente acima do nível do acaso: 73\%. Demuth et al. (2010) trazem dados de dezesseis crianças falantes do sesotho que não podem ser ignorados. Demuth (1989) argumenta que a função e a frequência das estruturas passivas são diferentes nas línguas, e isso pode influenciar seu processo de aquisição. Como mostra o estudo de Gabriel (2001), em PB contamos com outras estratégias sintáticas e funcionais que cumprem o papel da passiva de promover o "não agente". Assim, a função da sentença passiva, bem como sua frequência, não é tão saliente para crianças adquirindo o PB. O contrário parece acontecer em sesotho, em que a frequência da passiva é maior, já que a estrutura é utilizada para fazer perguntas sobre o sujeito, por exemplo. Dessa maneira, apesar de os dados do PB corroborarem a hipótese maturacional, ainda carecemos, na literatura, de uma proposta teórica que explique os dados das línguas em geral. Talvez somente uma proposta que leve em conta fatores maturacionais e fatores específicos da tipologia das línguas consiga dar conta de todos os fatos.

\section{REFERÊNCIAS}

BORER, H.; WEXLER, K. The maturation of syntax. In: ROEPER, T.; WILLIAMS, E. (Ed.) Parameter Setting, Massachusetts: Reidel, 1987.p. 123-172

BORER, H.; WEXLER, K. Bi-unique relations and the maturation of grammatical principles. Natural Language \& Linguistic Theory, v. 10, n. 2, mai 1992.

CHOMSKY, N. On binding. Linguistic Inquiry, v. 11, n. 1, p. 1-46, 1980.

CHOMSKY, N. Lectures on Government and Binding. Dordrecht: Foris, 1981.

DEMUTH, K. Maturation and the acquisition of the Sesotho passive. Language, v. 65, n. 1, p. 56-80, mar. 1989.

. The role of refrequency in language acquisition. In: GÜLZOW, I.; GAGARINA, N. (Ed.). Frequency effects in language acquisition. Berlin: Mouton De Gruyter, 2007. P. 383-388.

DEMUTH, K. et al. 3-year-olds' comprehension, production, and generalization of Sesotho passives. Cognition, v. 115, n. 2, p. 238 251, mai. 2010

FOX, D.; GRODZINSKY, Y. Children's passive: a view from the by-Phrase. Linguistic Inquiry, v. 29, n. 2, p. 311-332, 1998. 
GABRIEL, R. A aquisição das construções passivas em português e inglês: um estudo um estudo translinguístico. Tese (Doutorado em Letras) - Faculdade de Letras, Pontifícia Universidade Católica do Rio Grande do Sul, Porto Alegre, 2001.

JAEGGLI, O. A. Passive. Linguistic Inquiry, v. 17, n. 4, p. 587-622, 1986.

LIMA JR, J. C. Revisitando a aquisição de sentenças passivas em português brasileiro: uma investigação experimental com foco na compreensão. Dissertação (Mestrado em Letras) - Centro de Teologia e Ciências Humanas, Pontifícia Universidade Católica do Rio de Janeiro, Rio de Janeiro, 2012.

MARATSOS, M. et al. Some empirical issues in the acquisition of transformational relations. In: COLLINS, W. A. (Ed.). Minnesota Symposium on Child Psychology. v. 12. Hillsdale, NJ: Erlbaum, 1972.

Semantic restrictions on children's passives. Cognition, v. 19, n. 2, p. 167-191, 1985.

MENUZZI, S. The acquisition of passives in English and Brazilian Portuguese: regularities despite the input. Proceedings of Generative Approaches to Language Acquisition. Lisboa, 2002.

O'BRIEN, K. et al. Long passives are understood by young children. In: TSIMPLI, I. M. et al. (Ed.). Proceedings of the 30th Boston University Conference on Language Development, Somerville: Cascadilla Press, 2006. p. 441-451.

PEROTINO, S. Mecanismos de indeterminação do agente: o fenômeno da apassivação na aquisição da linguagem. $1995.128 \mathrm{f}$. Dissertação (Mestrado em Linguística) - Instituto de Estudos da Linguagem, Universidade Estadual de Campinas, Campinas, 1995.

PINKER, S. Language learnability and language development, with new commentary by the author. Boston: Harvard University Press, 2009.

RUBIN, M. Compreensão da passiva das crianças típicas. In: CELSUL - $6^{\circ}$ Encontro do Círculo de Estudos Linguísticos do Sul, 2006, Florianópolis - SC. Anais do $6^{\circ}$ Encontro do Celsul - Círculo de Estudos Linguísticos do Sul, 2004. v. 6.

. The passive in 3- and 4-year-olds. Journal of Psycholinguistic Research, v. 38, n. 5, p. 435-446, 2009.

Recebido em 21/07/2016. Aceito em 28/09/2016 